YASHASVI MEHTA

Pandit Deendayal Petroleum University, India

\title{
DETAILED STUDY ON FAMILY VALUES FROM DIFFERENT COUNTRIES AND HOW DIFFERENTIAL LEARNED BEHAVIOUR AND GENDER ROLES IMPACT ON CHILDREN'S PSYCHE AND ITS CONTRIBUTION TO ABUSE.
}

\begin{abstract}
:
Family values, defined as the lessons that are taught to the children regarding what is important in the family especially regarding gender roles. How the society and parents define and expect children of different genders to behave.

This paper focuses on the values and the morals that parents inculcate in their children and how do they differ when the region changes. Even among the same country the behaviour and the nurturing pattern of the child and parents changes. The focus is on how parents define and shape the child with reference to the gender, age, hierarchy, and social status.

The research also focuses on how gender roles change when the local, or country changes. It studies the change in expectations' of the society regarding how any gender is supposed to behave also what is considered masculine and feminine in different regions and how children are taught to adhere to those expectations.

Along with this, the research also focuses on how those expectations' lead to gender discrimination and what types of discrimination are the children subjected to in different regions. E.g. in India boys should be manly and to show that manliness, they are not expected to cry.

A small part of the research will also shed light on different kinds of abuse faced by the children for them to adhere to those gender roles while shedding light on the perpetrators of that abuse. And on the other hand how following those gender roles defines by the society makes the children not to speak up about the abuse in the society. How this affects the psychological welfare and the future of the child is studied in the research.
\end{abstract}

\section{Keywords:}

Family Values, Morals, Behaviour, Parenting, Change in Geography, Gender Roles, Gender Discrimination, Child Abuse, Society, Psychology. 


\section{Introduction}

Children at a very young age learn to differentiate between gender and their specific roles in today's society. Various things like activities, opportunities, encouragements, discouragements, overt behaviors, covert suggestions, and various forms of guidance, help children in the process of gender socialization. As children grow and develop, the gender stereotypes they are exposed to at home are reinforced by other elements in their environment and are thus perpetuated throughout childhood and on into adolescence (Martin, Wood, \& Little, 1990).

A child's sense of self is a result of the multitude of ideas, attitudes, behaviors, and beliefs that he or she is exposed to. The information that surrounds the child and which the child internalizes comes to the child within the family arena through parent-child interactions, role modeling, reinforcement for desired behaviors, and parental approval or disapproval (Santrock, 1994). These behaviors and believes are then reinforced by the society, friends and the media, television in particular. These socialization agents help the child to build believes and behavior pattern according to their roles and as the child develops, these then become a part of their self concept.

\section{Body}

The first major exposure to gender roles comes from a child's parents. Children are often dressed in gender specific clothing and given gender specific toys from birth, like boys playing with trucks and girls playing with dolls, encouraging them to participate in sex-typed play. Parents may also model gender normative behavior, both unintentionally and intentionally. Parental disapproval for failing to comply with gender norms and parental approval for successful compliance with these norms can serve to solidify children's understanding of gender roles.

The parental guidance and the level of discipline a child gets are related to their gender. In 2001, Claire Hughes found parents of young girls were more likely to have more positive overall affect and stronger discipline. She also found parental warmth to be associated with the development of theory of mind for girls, but not for boys. Hughes suggested this may have to do with a greater tendency for girls to use understanding of mind to seek emotional support, empathize, and cooperate.

It's typical for children to have gender identity that "matches" their biological sex. With the exception of those classified with gender identity disorder or gender dysphoria. The social impacts of imposing gender roles on children become evident very early in life and continue along their development. Alice Eagly In her book Sex Differences in Social Behavior: A Social-role Interpretation, affirms the idea that gender roles are a direct result of one's social interactions, calling social behavior "gender-stereotypic" and that most of the expectations of gender roles come from the stereotypes associated with them, such as a woman to be kind and compassionate and a man to be in control and independent.

Fagot (1990) found, children had a pronounced response when one of their peers violated their established gender role. Fagot's study shows the effect of gender segregation on children; boys tended to respond more readily to feedback from other boys while girls likewise responded to feedback from other girls. A study by Bandura and Bussey shows that kids want to be like others 
of their sex. They begin labeling objects as "for girls" or "for boys" and conform to what is expected of them.

Carol Martin (1990) observed that cross-sex behavior is generally discouraged in both sexes, more so in males. Gender roles place constraints upon what a child is allowed to do, based upon what their peers deem is acceptable.

Children fall into these patterns with little guidance from either parents; thus they are instinctually drawn to members of the same sex and begin to adopt behavior that is considered gender appropriate. This is known as self-socialization and it drives the interaction between children throughout their young lives. This instinctive segregation encourages the gap between males and females and helps to reinforce gender roles as the child continues to grow.

A study by university of Michigan outlines the fact that gender stereotyping and enforced adherence play a major role in abuse. Girls are taught to be passive, smile, be nice, accommodating, take care of and be sensitive to other's needs. Beyond "teaching," their culture actively punishes girls who violate those rules. Such punishment includes social ostracism, ridicule, poor grades in school, and often times sexual harassment, assault, and physical violence. As a result, girls soon learn the price of speaking out, independence and autonomy. Individual females may have these lessons softened or more strictly enforced by their own particular family members, extended family, neighborhood, school and teachers, but the overall cultural message remains constant. The concept of male entitlement created by gender roles is associated with domestic violence. Men have been taught through social roles modeling and the media that they are entitled to the attention and services of women. Women are required to listen, be supportive, enhance their partners' status with other men, fulfill the man's sexual needs, and care for their children. Traditional gender roles maintain the expectation that women are required to cook, clean and maintain the household, having created a dynamic within intimate relationships that maintain women as subservient and men as power holders and decision makers, which is ultimately detrimental to the health and survival of women. Often not reaching these expectations leads to violence by men.

It also outlines how these roles are so deeply engrained in many men and women that it makes it difficult to uncover the extent to which behavior has been influenced by socialization. However, there are men who have chosen non-violence, and are actively participating in equal relationships with women and working to challenge male privilege. It is encouraged that all men take a greater role in challenging violence and sexism.

Women are indoctrinated with the notion that they are only valuable if, they are in or seeking out heterosexual relationships and, they have children. In addition, the pressure of maintaining a family is evident upon many women in their culture, taught to believe that they are responsible for their family, its health and well-being. Again, gender roles suggest that women are to be nurturing, caring, and self-sacrificing. These beliefs work against women who become trapped by violent men. When women do what they have been taught to do and are then blamed for staying. They are labeled masochistic or codependent. Some battered women stay because in addition to being women and being battered, they are from another historically disenfranchised population. 


\section{Comparison between different regions}

A 2010 study by the Family Acceptance Project at San Francisco State University that focused mainly on adolescents found strong correlations between positive family attitudes toward their lesbian, gay, bisexual and transgender children and decreased risks of depression, substance abuse and suicide.

A survey conducted by survelum showed that in US, $92 \%$ of the people believed that gender bias still existed. And $46 \%$ believed that men experience a tremendous amount of social pressure to behave masculine and tough. $62 \%$ stated that men and women are not treated equal in western society. The most popular words associated with women were physical beauty; nurturing and least popular were violence and inventiveness. When it comes to men the words mostly associated with them were aggression and attention to job/career and the least popular were nurturing and tendency to be fearful. (survelum public data bank - gender roles and stereotype survey).

Children in this society learn at a very young age that there are differences between boys and girls. This idea permeates daily life and is encouraged by parents, peers, school, and the media. Little girls learn that they are supposed to like dolls and pink, while little boys learn that they are supposed to like trucks and the colour blue. Through various forms of guidance and direction from external influences, children experience gender role socialization (Albert, 1988). The stereotypes that adults hold pertaining to gender roles has a significant influence on children. Adults may inadvertently reward or punish children on the basis of these stereotypes. Children may also form their own stereotypes based on the stereotypes they observe in the adults within their environment (Martin, 1995). Adults, whether intentionally or not, influence children in regard to gender role socialization through the family, media and school system.

Governments in Europe are typically more active in governing the lives of their citizens than the U.S. government. As such, European governments have used their social powers to encourage equality between men and women.

In Sweden, for example, all working parents are entitled to sixteen months paid leave per child, with the cost shared by the government and the employer. To encourage greater paternal involvement in childrearing, a minimum of two months out of the sixteen is required to be used by the "minority" parent, usually the father. Through policies such as parental leave, European states actively work to promote equality between genders in childrearing and professional lives. It also encourages and teaches the children to break the steryotypical gender roles and learn from small examples.

Women in Chile feel pressure to conform to traditional gender roles. A 2010 study by the United Nations Development Programme found that $62 \%$ of Chileans are opposed to full gender equality and expressed the belief that women should limit themselves to the roles of mother and wife. These social barriers to gender equality exist in the face of legal equality.

However, Chilean government has made some changes to promote gender equality. Changes like being able to handle her own property after marriage, demolition of the low that stated that women should be faithful after marriage, and having one of the first female president in the world, mean that Chile is moving toward equality. 
Women in Japan are usually well-educated and employed, though gender dynamics emerge in regards to social pressure to find a husband. However, gender inequality continues in family life, the workplace, and popularvalues. A common Japanese proverb that continues to influence gender roles is "good wife, wise mother." The proverb reflects the still common social belief, encouraged by men and women alike, that it is in the woman's, her children's, and society's best interests for her to stay home and devote herself to her children.

A survey conducted by me in India shows the relation of gender roles and how are they taught to children. The results show that there are different norms and ways that gender roles are taught to children. $62 \%$ of Gujarati population answered that girls are expected to behave in a certain way and follow the traditional gender roles of being a homemaker, while $73 \%$ of Bengali stated that they are not expected to follow those social norms and choose the field that they want to pursue. However, most of the females answered that in there society men are superior to women. When asked whether they were bullied for not being masculine or feminine enough $40 \%$ answered yes. Most of the men answered that they as men they felt that they have to be strong and the bread bearer for the household.

\section{Relation to abuse}

A study to show the relation to abuse concluded that Younger men reported experiencing higher levels of emotional abuse, which declined with age. Older females reported experiencing less emotional abuse than older males. Overall, emotional abuse was more common in younger participants. Younger women experienced higher rates of isolation

An article by Jane Collingwood concludes that men who do not feel they live up to traditional masculine gender norms may be more prone to violence. Analysis indicated that men high on gender role discrepancy and attendant discrepancy stress reported significantly more assaults with a weapon and assaults causing injury.

"Gender role discrepancy and associated discrepancy stress, in particular, represent important injury risk factors and that prevention of discrepancy stress may prevent acts of violence with the greatest consequences and costs to the victim, offender, and society," the authors write in the journal Injury Prevention. "Masculine socialization and acceptance of gender norms may induce distress in boys and men."

However, there was no link with drug or alcohol abuse. "This may suggest that substance use/abuse behaviors are less salient methods of demonstrating traditional masculinity in contrast to behaviors related to sex and violence, perhaps due to the potentially private nature of the habit," the researchers suggest.

Research on masculinity suggests that gender roles influence males' sexual health by encouraging risk-taking behavior, discouraging access to health services, and narrowly defining their roles as partners. However, despite the propensity of highly masculine men to engage in high-risk sexual behavior, there is reason to suspect that men at the other end of the continuum may still be driven to engage in similar high-risk behaviors as a consequence of gender socialization (Centers for Disease Control and Prevention). 


\section{Conclusion}

At a young age children learn to observe the world around them and start learning from the observations. Books, people, society, peers, etc help shape the child's gender identity. Gender roles are learned through social interactions, experiences, etc. Parents and teachers play a role in helping a child learn about gender through many things like, toy selection (toys based on gender), play (parents, especially fathers often engage in more "gender appropriate play"), chores (gender discrimination can often be seen in chores i.e. girls might do more household chores than boys) and through the work they're supposed to do at school.

A child's attitude to gender will affect his/her attitude when they get older. The wrong impression might limit boys from being nurses, child care workers or cooks and likewise stop girls from becoming air-line pilots or brick layers. Ultimately this leads to a situation where they may not be motivated to achieve their full potential. This type of discrimination can also have a big affect on the children and their families, which can lead to family dysfunction, problems and health issues.

Being discriminated against could also damage the child's self-confidence, growing up with an "inferior" view of themselves and refusing to try new activities because it is not expected of their gender to do so. In turn this could damage their social relationships in the future.

Within the family setting, boys might not expect to help with housework, like doing dishes or cleaning up if they are encouraged to think this is not appropriate for their gender.

Because children learn through example and mimicking same-gender adults, parents therefore have a big role to play in teaching children about gender and help them differentiate between right and wrong.

However society now seems to gradually accept that girls can also share the traditional male active/assertive/dominant roles and boys can also share the traditional female caring/cooking/sensitive roles; one solution can be that early education should contain a balance of traditional and non-traditional roles for both boys and girls which helps them to reach their full potential and not be barricaded by the concept of socially excepted gender roles.

\section{References}

Gender Identity and Gender Confusion in Children. (11 May 2013). HealthyChildren.org. Retrieved 11 November 2013

Oskamp, S.; Kaufman, K.; Wolterbeek, L. (1996). "Gender Role Portrayals in Preschool Picture Books". Journal Of Social Behavior \& Personality.

Witt, Susan D. Parental Influences on Children's Socialization to Gender Roles. CalPoly College of Liberal Arts. Retrieved 11 November 2013

Hughes, C.; Deater-Deckard, K.; Cutting, A. L. (1999). "'Speak roughly to your little boy'? Sex Differences in the Relations Between Parenting and Preschoolers' Understanding of Mind". Social Development. 
Bartlett, N. H.; Vasey, P. L.; Bukowski, W. M. (2000). "Is Gender Identity Disorder in Children a Mental Disorder?.". Sex Roles. 43 (11/12): 753-785.

Eagly, A. H. Sex Differences in Social Behavior: A Social-role Interpretation. Hillsdale, NJ: L. Erlbaum Associates, 1987. Google Books. 13 May 2013. Web. 11 Nov. 2013.

Parke, R. D., \& Gauvain, M. (2009). "Gender Roles and Gender Differences." Child Psychology: A Contemporary Viewpoint. 7th ed. Boston: McGraw Hill, 2009. 475-503. Print.

Bussey, K.; Bandura, A. (1999). "Social Cognitive Theory of Gender Development and Differentiation". Psychological Review. 106 (4): 676-713.

Martin, C. L. (1990). "Attitudes and Expectations about Children with Nontraditional and Traditional Gender Roles". Sex Roles. 22 (3-4): 151-66.

Martin, C. L.; Fabes, R. A. "The Stability and Consequences of Young Children's Same-sex Peer Interactions". Developmental Psychology. 37 (3):

External Influences of Children's Socialization to Gender Roles

Sarah A. Chartschlaa

Violence Linked to Gender Roles - Jane collingwood

https://psychcentral.com/news/2015/12/12/violence-linked-to-gender-roles/96133.html

www.wikipedia.com

https://sapac.umich.edu/article/323

http://www.survelum.com/survey-results/darkchocolate/

http://www.lo.zyrardow.edu.pl/COMENIUS/Preview/results-of-the-survey-on-gender-role-stereotypes--conclusions---poland.html

http://www.nytimes.com/2011/06/12/fashion/new-challenge-for-parents-childrens-gender-roles.html www.pitlanemagazine.com

www.psychcentral.com

https://www.boundless.com/sociology/textbooks/boundless-sociology-textbook/gender-stratification-andinequality-11/gender-and-socialization-86/the-cross-cultural-perspective-499-10465/ 